MOON

\section{First Impressions}

By the time the lunar samples brought back by Apollo 11 have been wrung dry of scientific information, the second American expedition to the Moon will have already been mounted. Almost certainly, the next landing will be at one of the two sites in the eastern hemisphere which have been chosen as smooth enough for a landing - both sites are near the equator in Oceanus Procellarum. This way by the end of the year NASA will have recovered samples of typical mare regions in both the eastern and western hemispheres of the visible face of the Moon. What the Apollo 12 astronauts-Charles Conrad and Alan Bean on the surface and Richard Gordon in the command module-will be instructed to look out for will depend on the first-hand descriptions of the surface radioed by Armstrong and Aldrin on Monday morning (BST) and on preliminary analyses of the samples. Already the astronauts' impressions of the surface material are adding to what has been inferred from the crude chemical and mechanical analyses carried out by the Surveyor soft-landers. The experimenters fortunate enough to be on NASA's distribution list now have a better idea of what to expect.

Armstrong's first description that "the surface appears to be very finely grained as you get close to it, it's almost like a powder" matches the Surveyor results which point to a matrix made up of finely divided particles sometimes aggregated in lumps. That the surface took a clear imprint of treads on Armstrong's boots was expected from the impressions left by a pattern inscribed to a depth of 50-70 microns on the Surveyor footpads, which implies that much of the moondust must be finer than 60 microns. The cloud of dust raised by the descending lunar module at a height of 70 feet must have consisted of this fine material. A few minutes later Armstrong recorded that "it's a very soft surface, but here and there where I plug in the contingency sample collector, I run into a very hard surface, but it appears to be very cohesive material of the same sort". Some of the hard rocks collected in the contingency sample had what seemed to be vesicles in the surface, and one seemed to have some sort of phenocryst-a prominent embedded crystal.

Later Aldrin found some purple rocks containing what he guessed to be biotite, a mica which can be green, brown or black found in terrestrial granites and in the lavas of Vesuvius. Armstrong described some boulders as looking like basalt and having probably 2 per cent white minerals in them. The rock seemed to be peppered with tiny impact craters. At one stage one of the astronauts described the soil as a greyish cocoa colour.

The mechanical properties of the soil are much as the Surveyor data predicted. Aldrin said: "I could suggest exactly what the Surveyor pictures showed when they pushed away a little bit. You get a force transmitted through the upper surface of the soil and about five or six inches of bay breaks loose and moves as if it were caked on the surface when, in fact, it really isn't." Armstrong noticed that the soil is very cohesive and will retain a slope of probably $70^{\circ}$. This seems to have been the kind of phenomenon with which powder metallurgists are familiar-rough powders more easily transfer stresses to each other.

What seems to have been surprising was the lack of damage to the surface caused by the impact of the lunar module and the blast of its engine. According to Armstrong's preliminary inspection, "The descent engine did not leave a crater of any size. ... I can see some evidence of rays emanating from the descent engine, but very insignificant amounts."

\section{LUNAR SURFACE}

\section{What is the Surface Like?}

FIRsT reactions by British scientists who are to receive lunar samples centred on the handful of mineralogical references in the astronauts' comments, and on their descriptions of the consistency of the surface material.

Aldrin's mention of biotite caused most comment. Dr N. J. Snelling of the Institute of Geological Sciences, where the mineralogy and distribution of radioactive materials in the samples are to be investigated, found the reference to biotite surprising. The surface material could be generally basaltic, as the Surveyor softlanders seemed to suggest (although a reconsideration of the Surveyor results has laid seeds of doubt about this interpretation), or it could be meteoritic debris; in neither case is biotite expected. If it is not a case of misidentification, the biotite almost certainly indicates volcanic material which has undergone more chemical processes than one might have expected on the Moon. On the other hand, Dr S. W. Richardson of the Grant Institute of Geology, University of Edinburgh, where the crystal structure in the samples is to be investigated for hints of the conditions under which crystallization took place, doubted that Aldrin was close enough to the rock he was describing to identify biotite. But he pointed out that the mention of phenocrysts suggested a rock which had crystallized at moderate or shallow depths. If biotite was indeed present, then the rocks must be highly differentiated and there must have been a high partial pressure of water. The white mineral which Armstrong mentioned in a rock which scemed to be basalt is probably plagioclase feldspar. Professor J. Zussman of the Department of Geology at Manchester University agreed that the identification of biotite is doubtful considering the conditions under which the astronauts were working. Many other minerals glint in the same way as biotite.

The vesicular appearance of the rocks was interpreted by Professor Zussman and by Dr Snelling as indicating a lava extruded in vacuum conditions, so that gas bubbles leave the rock looking like a sponge. Terrestrial lava flows have the same appearance. An alternative possibility is that the vesicles are tiny impact craters.

Professor G. M. Brown of the Department of Geology, Durham University, where a petrological examination of samples is to be undertaken, thought that the astronauts posed as many problems as they answered. Biotite is difficult to account for because of its water content, and there is the problem of explaining the extremely finely divided nature of the surface soil. The references to the slipperiness are also hard to 